\title{
Appendicectomy in private practice in KwaZulu-Natal Province, South Africa
}

\author{
R P Mills, ${ }^{1}$ MB ChB, FRCS (Ed); D L Clarke, ${ }^{2,3}$ MB BCh, MPhil, MBA, PhD, FCS (SA); V Y Kong, ${ }^{2}$ MB ChB, MSc, PhD, MRCS (Ed) \\ ${ }^{1}$ Private Practice, Life Entabeni Hospital, Durban, South Africa \\ ${ }^{2}$ Department of Surgery, Pietermaritzburg Hospital Complex and Nelson R Mandela School of Medicine, University of KwaZulu-Natal, Durban, \\ South Africa \\ ${ }^{3}$ Department of Surgery, Faculty of Health Sciences, University of the Witwatersrand, Johannesburg, South Africa
}

Corresponding author: D L Clarke (damianclar@gmail.com)

\begin{abstract}
Background. The treatment of appendicitis is regarded as a bellwether procedure that can be used to describe the delivery of essential surgical care. Little has been published on clinical outcomes in the private sector in South Africa (SA), and this study attempts to address this deficiency.

Objectives. To extend our understanding of the outcomes of acute appendicitis in the public and private sectors in SA.

Methods. Data on patients covered by a leading medical aid who underwent appendicectomy in 26 private hospitals in Durban and Pietermaritzburg, KwaZulu-Natal Province, during the period 2010 - 2015 were obtained and compared with existing data from a recent study of patients with appendicitis treated in the Pietermaritzburg academic complex.

Results. Between January 2010 and December 2015, 397 patients covered by the medical aid underwent appendicectomy in private hospitals. Their mean age was 29.7 years (range 3.7 - 87.6), the mean length of stay 4.6 days (range 1 - 41) and the mean operation time 70.6 minutes (range 24.0 - 335.0). Of the procedures 66.5\% were laparoscopic. A total of 33 patients (8.3\%) required intensive care unit (ICU) admission, and $38(9.6 \%)$ were readmitted. While there was no information on the reasons for readmission, this is a proxy marker for possible complications. The mean total event cost per patient was ZAR38 934. A total of 134 open operations were performed (33.8\%). In the state sector, a total of 1004 patients were documented. The mean patient age was 20.2 years (difference not statistically significant), mean length of stay was significantly longer at 7.3 days ( $p=0.02$, one-tailed $t$-test), and $10 \%$ of patients required ICU admission. In the state hospitals only $3 \%$ of the operations were laparoscopic. None of the private sector patients but $40 \%$ of the state patients required further surgery.

Conclusions. Medical aid data provide useful information on disease profiles and outcomes in private practice. The outcome of acute appendicitis in the private sector appears to be significantly better than in the state sector. Further work is required to fully elucidate the reasons for this, although late presentation in the state patients almost certainly contributes to their poor outcome. In terms of cost, SA private practice appears to be highly efficient and is relatively inexpensive in comparison with international equivalents.
\end{abstract}

S Afr Med J 2018;108(10):836-838. DOI:10.7196/SAMJ.2018.v108i10.13151

Healthcare in South Africa (SA) is delivered by two main systems, a public sector serving $\sim 80 \%$ of the population and a private sector serving the remaining $20 \% .{ }^{[1]}$ The population cohort presenting to the public sector is generally from the lower income group and faces major resource constraints in terms of ability to access healthcare services. Patients who utilise private healthcare come from the middle and upper income groups and generally have medical aid cover and/or medical insurance.

There is increasing political pressure to move towards an integrated single healthcare service in SA, so accurate assessment of performance in the public and private sectors is essential. There is a perception that the public sector is beleaguered and beset by logistic and capacity challenges owing to a complex interaction of historical and contemporary factors. The private sector, on the other hand, is perceived as being focused on profit and catering for diseases of affluence.

There is very little research comparing diseases and outcomes in the private and public sectors, and this adds to the challenge of meaningfully discussing policy options and strategies for a unified health system. Private healthcare practitioners have autonomous, mostly individual practices, making it difficult to obtain overall outcome statistics. Surgeons generally practise in isolation and the focus is very much on service delivery and financial accounting. There is no recognised or official process of medical audit in this sector. A source of clinical information that has been largely ignored to date is data from medical aid schemes. These data could be used for comparative statistical analysis and an overview of common pathologies.

Acute appendicitis is a common surgical disease that should have minimal morbidity if diagnosed early and treated appropriately. ${ }^{[2-6]}$ As such, it has been proposed as a surrogate or proxy outcome marker for the quality of surgical care delivered by a healthcare system. ${ }^{[2]}$ Disparities in outcome between different patient cohorts are likely to represent differences in the quality of healthcare available to these groups ${ }^{[2-7]}$ Existing data suggest that there is a difference in outcome between private and public patients with acute appendicitis in SA, although more in-depth analysis is needed. ${ }^{[2-7]}$

\section{Objectives}

To extend understanding of the outcomes of acute appendicitis in the public and private sectors in SA. Aggregated data on appendicectomy from a single healthcare funder were analysed and compared with existing data sets from the state sector to try to highlight differences in the spectrum and outcome of appendicectomies in the 
two sectors. We hoped that this would provide a comparative analysis of private and public surgical care in our region and help in health policy planning.

\section{Methods}

Data on patients covered by a leading medical aid who underwent appendicectomy in 26 private hospitals in Durban and Pietermaritzburg, KwaZulu-Natal Province, during the period 2010 2015 were obtained. The funder had the following information available: age, gender, ethnicity, length of hospital stay, date of operation, open or laparoscopic surgery, intensive care unit (ICU) admission and need for readmission within 30 days. While there was no information on the reasons for readmission, this is a proxy marker for possible complications. The data were compared with existing contemporaneous (2010 - 2013) data from recent studies of patients with appendicitis treated in the Pietermaritzburg hospital complex. ${ }^{[2-4,6,8]}$ Statistical analysis was performed in Microsoft Excel version 1807 (Microsoft, USA) using Student's $t$-test to compare the means of each parameter.

The funder provided a detailed cost analysis for each patient. The average cost of each appendicectomy was compared with the average cost of treating acute appendicitis at a major state regional institution, taken directly from a previously published costing of acute appendicitis. ${ }^{[7]}$

We obtained ethics approval to undertake this study from the University of KwaZulu-Natal Biomedical Research Ethics Committee (ref. no. BE 337/12).

\section{Results}

\section{Private sector data}

Between January 2010 and December 2015, 397 patients covered by the medical aid scheme underwent appendicectomy in the 26 private hospitals. Their mean age was 29.7 years (range 3.7 - 87.6), the mean length of stay 4.6 days (range 1 - 41) and the mean operation time 70.6 minutes (range 24.0 - 335.0). A total of 33 patients $(8.3 \%)$ required ICU admission and $38(9.6 \%)$ were readmitted within 30 days. No private patient needed repeat surgery. A total of 133 open operations were performed (33.5\%). Mean length of stay was longer for the open group than for the laparoscopic group, at 5.3 days v. 4.2 days $(p=0.02$, one-tailed $t$-test). There was no statistical difference in mean operation time between laparoscopic and open groups (Table 1).

The mean total event cost per patient in the private sector was ZAR38 934. Fig. 1 shows the spread of cost for the private sector.

\section{Comparison with state patients}

The mean age of patients treated in the state sector was 20.2 years. This was not statistically significantly different from the mean age of the private patients ( $p=2.2$, two-tailed $t$-test). Mean operation time did not differ significantly between the two groups, but mean length of stay in the state sector (7.3 days) was significantly longer than in the private sector $(p=0.02$, one-tailed $t$-test). Ten percent of state patients required ICU admission, and $40 \%$ required further surgery (Table 2). The average cost of an appendicectomy in the state sector in Pietermaritzburg was calculated as ZAR21 364, compared with the mean of ZAR27 492 paid out to private hospitals by the medical aid for the same procedure.

\section{Discussion}

There is increasing realisation that the outcome of appendicectomy is a potential marker of the quality of surgical care in a health system. ${ }^{[2-4]}$ Acute appendicitis is a common disease that is treated definitively by a relatively simple surgical operation. If it is diagnosed early and treated appropriately, surgery is curative and morbidity minimal. If there is delay in management, or if management is inappropriate, morbidity and cost rise dramatically. ${ }^{[8]}$ Poor outcomes for appendicectomy therefore reflect systemic failures in a healthcare system. ${ }^{[2,3]}$ For this reason, appendicitis is a useful disease and appendicectomy a useful procedure for planners and administrators to use to track the quality of care in a system.

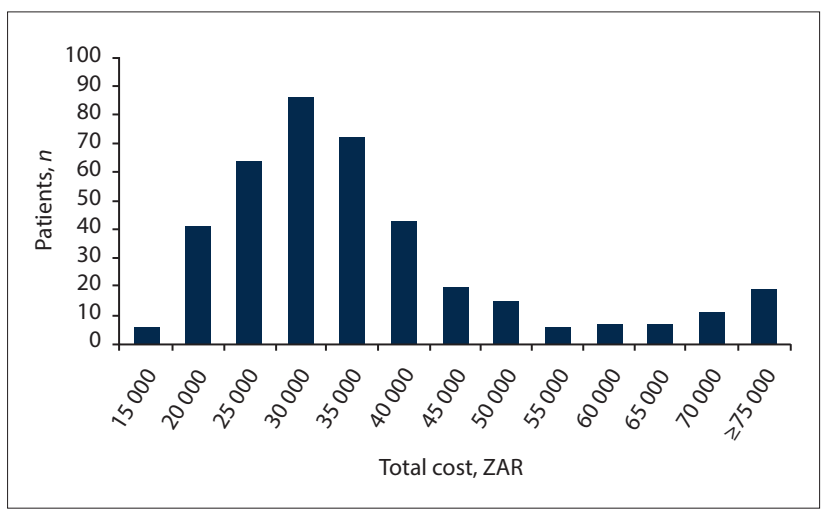

Fig. 1. Total event cost of appendicectomy in the private sector.

\begin{tabular}{llll}
\multicolumn{4}{l}{ Table 2. Comparison between private and state patients } \\
\hline & $\begin{array}{l}\text { Private } \\
(N=397)\end{array}$ & $\begin{array}{l}\text { State } \\
(N=1 \text { 004) }\end{array}$ & p-value \\
\hline Mean age (years) & 29.7 & 20.2 & $2.2(\mathrm{NS})$ \\
Male, \% & 46 & 54 & \\
Ethnic group, \% & & & \\
$\quad$ Black African & 7 & 100 & \\
$\quad$ Asian & 18 & 0 & \\
$\quad$ White & 63 & 0 & \\
$\quad$ Coloured & 2 & 0 & \\
Mean length of stay (days) & 4.6 & 7.3 \\
Laparoscopic, \% & 66 & $3-5$ & \\
Specialist surgeon at & 100 & 15 & \\
operation, \% & & & \\
Need for ICU, \% & 8 & 10 & \\
Repeat surgery, \% & 0 & 40 & \\
Hospital cost, ZAR & 27492 & 21364 \\
Mortality, \% & 0 & 1 \\
NS = not significant; ICU = intensive care unit. & & \\
& &
\end{tabular}

Table 1. Comparison between laparoscopic and open appendicectomy $(N=397)$

\begin{tabular}{llllll}
\hline \multicolumn{1}{l}{ Age (years) } & $\begin{array}{l}\text { Length of stay } \\
\text { (days) }\end{array}$ & $\begin{array}{l}\text { Theatre time } \\
\text { (minutes) }\end{array}$ & Total event cost (ZAR) & Total hospital cost (ZAR) \\
\hline $\begin{array}{l}\text { Laparoscopic }(n=264, \\
66.5 \%), \text { mean (range) }\end{array}$ & $30.8(4.3-87.6)$ & $4.2(1.0-41.0)$ & $71.5(31.0-335.0)$ & 37660.61 & 26783.25 \\
$\begin{array}{l}\text { Open }(n=133,33.5 \%), \\
\text { mean (range) }\end{array}$ & $27.6(3.7-82.3)$ & $5.3(2.0-21.0)$ & $68.8(24.0-232.0)$ & 41463.31 & $(11257.5-212533.2)$ \\
& & & & $(11900.08-332574.83)$ & $(7187.45-258612.68)$
\end{tabular}


A great deal of research has been done over the past decade on the outcomes of acute appendicitis in SA in general and in KwaZuluNatal in particular. ${ }^{[3-6]}$ This work has focused on patients in the state sector, with only a single recent study focusing on the spectrum and outcome of acute appendicitis in a small sample from the private sector in Cape Town. ${ }^{[6]}$ Comparative outcome studies for other surgical diseases are lacking, and there is a need for more data from the private sector to compare with the public sector and analyse how these two dichotomous systems could perform better to improve healthcare outcomes.

The present study has attempted to address this deficit, using medical aid data to obtain a comparative overview of acute appendicitis in SA. The majority of private patients are white, whereas the majority of state patients are black African. The age range is similar between the two groups. The data suggest that outcomes differ significantly. Length of hospital stay was significantly longer for the state patients, suggesting a more complicated postoperative course. In addition, the need for repeat surgery was extremely high in the state sector, while in the private patients it was non-existent. This almost certainly reflects more severe disease in the state patients. This increased severity of disease in SA state sector patients has been shown in studies comparing SA patients with international cohorts. It would appear that it also holds true when comparing state and private sector patients within the country. This probably reflects barriers in access to healthcare in the state sector. There are many possible reasons for this, and further work is needed to elucidate them.

Use of laparoscopic surgery in the management of acute appendicitis is limited in the state sector but widespread in the private sector. The reasons for this are unknown, but probably include issues around access to laparoscopic equipment as well as levels of skill of the surgeons performing the majority of the surgery for acute appendicitis. Whether this affects outcome is unclear and needs further study.

The cost of appendicectomy in the private sector is slightly higher than in the state sector. The significance of this price difference is difficult to interpret. The documented severity of disease in the state sector patients translates into a very high rate of reoperation, which would increase costs dramatically. It is very difficult to compare costs directly without access to information on the grade of disease being managed in the state and private sectors. The data suggest that the private sector in SA is relatively cost-effective in its management of acute appendicitis. ${ }^{[9]}$ The available data comparing cost in the private sector in SA with the private sectors in other countries (Fig. 2) seem to support this assertion.

\section{Study limitations}

There are major limitations with the use of medical aid data. The fact that there is very little information on the severity or grade of the disease profile makes it difficult to compare data sets. Development and use of standardised reporting grades for the severity of acute appendicitis may make more meaningful comparisons possible in the future. There is also no reporting of morbidity in the medical aid data, and clinical and operative notes are not available for review. This means that funder data can only provide an overview of a disease. However, with the current paucity of data on surgical conditions in general, the aggregated data available from healthcare funders may serve as a readily available source of information that may allow for a more evidence-based discussion around future healthcare planning.

\section{Conclusions}

Medical aid data provide useful information about disease profiles and outcomes in private practice. The spectrum and outcome of

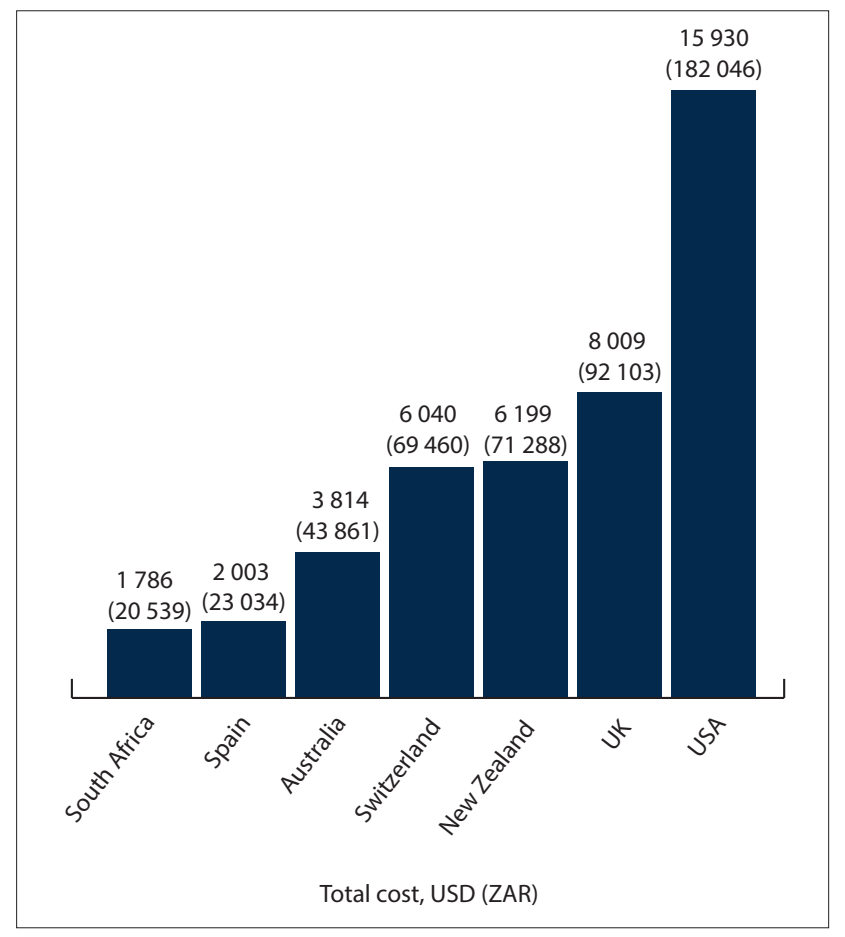

Fig. 2. International Federation of Health Plans, 2016 Comparative Price Report: ${ }^{[9]}$ Appendicectomy (cost in USD, with ZAR equivalent in parentheses).

patients requiring appendicectomy in private practice differ from those in the state sector. Further study is needed to elucidate the reasons for this. In terms of cost, SA private practice appears to be highly efficient. Medical aid data may be a useful source of readily available information to inform the various debates around health policy in SA.

Acknowledgements. Momentum Health.

Author contributions. RPM: private sector data and comparison analysis; VYK and DLC: state sector data, comparison analysis and overall coordination.

Funding. None.

Conflicts of interest. None.

1. Chopra M, Lawn JE, Sanders D, et al; Lancet South Africa team. Achieving the health Millennium Development Goals for South Africa: Challenges and priorities. Lancet 2009;374(9694):1023-1031. https://doi.org/10.1016/S0140-6736(09)61122-3

2. Clarke DL, Kong VY, Handley J, Aldous C. A concept paper: Using the outcomes of common surgical conditions as quality metrics to benchmark district surgical services in South Africa as part of a systematic quality improvement programme. S Afr J Surg 2013;51(3):84-86. https://doi.org/10.7196/ sajs. 1476

3. Hernandez MC, Finnesgaard E, Aho JM, et al. Appendicitis: Rural patient status is associated with increased duration of prehospital symptoms and worse outcomes in high- and low-middle-income countries. World J Surg 2018;42(6)1573-1580. https://doi.org/10.1007/s00268-017-4344-5

4. Kong VY, van der Linde S, Aldous C, Handley JI, Clarke DL. Quantifying the disparity in Kong VY, van der Linde S, Aldous C, Handley JJ, Clarke DL. Quantifying the disparity in
outcome between urban and rural patients with acute appendicitis in South Africa. S Afr Med J outcome between urban and rural patients with acute appendicitis in South Africa. S Afr Med J
2013;103(10):742-745. https://doi.org/10.7196/SAMJ.7109 2013;103(10):742-745. https://doi.org/10.7196/SAMJ.7109

5. Yang E, Kahn D, Cook C. Acute appendicitis in South Africa: A systematic review. S Afr J Surg 2015;53(3 and 4):31-38.

6. Kong VY, Sartorius B, Clarke DL. Acute appendicitis in the developing world is a morbid disease. Ann R Coll Surg Engl 2015;97(5):390-395. https://doi.org/10.1308/003588415X14181254790608

Yang E, Cook C, Kahn D. Acute appendicitis in the public and private sectors in Cape Town, South Africa. World J Surg 2015;39(7):1700-1707. https://doi.org/10.1007/s00268-015-3002-z

8. Kong V, Aldous C, Handley J, Clarke D. The cost effectiveness of early management of acute appendicitis underlies the importance of curative surgical services to a primary healthcare programme appendicitis underlies the importance of curative surgical services to a primary healthcare program
Ann R Coll Surg Engl 2013;95(4):280-284. https://doi.org/10.1308/003588413X13511609958415

9. International Federation of Healthcare Plans. 2016 Comparative Price Report. http://www.ifhp. com/1609217/ (accessed 17 March 2018)

Accepted 12 April 2018. 